\title{
Comunicación

\section{Un mapa para caminar a través del campo de la comunicación en Iberoamérica}

\author{
JUAN LARROSA-FUENTES 1
}

Tres tonos, tres voces y tres emplazamientos distintos. Éstas son algunas de las características más importantes del libro Qué pasa con el estudio de los medios. Diálogo con las Ciencias Sociales en Iberoamérica, publicado por Comunicación Social y firmado por Raúl Fuentes Navarro, Raúl Trejo Delarbre y Enrique Sánchez Ruiz. Dicho libro contiene una serie de mapas que ayudarán al lector a reconocer los rasgos más generales del estudio de los medios de comunicación, sus orígenes, sus tradiciones y sus rupturas.

El primer capítulo, titulado "Condiciones institucionales para la práctica de la investigación académica de la comunicación: la persistencia de la triple marginalidad en México", es aportación de Raúl Fuentes Navarro, profesor e investigador del Departamento

1 Intituto Tecnológico y de Estudios Superiores de Occidente, México.

Correo electrónico: larrosa@iteso.mx. 
de Estudios Socioculturales del Instituto Tecnológico y de Estudios Superiores de Occidente (ITESO) y también del Departamento de Estudios de la Comunicación Social (DECS) de la Universidad de Guadalajara (UdeG). Una de las líneas de investigación más importantes de Fuentes Navarro es el estudio del campo académico de la comunicación (meta-investigación), y a ella dedica el capítulo que se presenta en este libro.

El texto de Fuentes se compone de tres grandes bloques. El primero de ellos es la construcción de una fotografía detallada sobre el campo académico de la comunicación en México, lo cual parte de una narración histórica sobre su constitución y posterior desarrollo. En un segundo momento explica que a pesar de dos décadas de trabajo se han dado cambios y avances importantes en el campo académico de la comunicación, aún persiste una "triple marginalidad", pues "la investigación de la comunicación es marginal dentro de las ciencias sociales, éstas dentro de la investigación científica en general, y ésta última a su vez entre las prioridades de desarrollo nacional" (p. 17). En un tercer apartado, Fuentes hace una reflexión sobre la institucionalización de los estudios de comunicación y la relación que éstos sostienen con las distintas disciplinas que conforman el gran corpus de las ciencias sociales. En este andar, la postdisciplinariedad, entendida como un "eclecticismo metodológico en la investigación y la enseñanza" (p. 40), se ha convertido en una opción importante para un campo que no pocas veces se rehúsa a ser encasillado en la sociología, la antropología o la lingüística -y que por el contrario, toma de ellas, y de otras disciplinas más- aquellos elementos que ayuden a edificar sus objetos de estudio.

El segundo texto del libro lo presenta Raúl Trejo Delarbre, un experimentado académico avecindado en la Ciudad de México y con su centro de operaciones en el Instituto de Investigaciones Sociales de la Universidad Autónoma de México (UNAM). Su capítulo se titula "El tronco, el árbol, la enramada. La investigación de los medios de comunicación y las Ciencias Sociales" y en él reconstruye un mapa de sus propias lecturas en el vasto campo de la comunicación.

Trejo Delarbre, quien a lo largo de sus más de tres décadas de trabajo ha incursionado en diversas investigaciones y publicado 16 
libros de su autoría, comienza reflexionando sobre el origen de la adscripción de los estudios sobre medios de comunicación. En este primer acercamiento, desarrolla la metáfora expresada en el título de su texto y argumenta que:

El estudio de los medios adquiere metodologías, formas de propagación y tradiciones tan específicas que muchos de quienes las practican han considerado que tienen su propio árbol. Otros, en cambio, han querido cobijarse en la generosa hojarasca de las ciencias sociales; a veces llegan a considerar que el estudio de los medios es como un arbolito que brotó a la sombra del tronco mayor, compartiendo raíces pero sin poder crecer debido precisamente a que está demasiado cerca de él (pp. 57-58).

Para Trejo es muy importante discutir desde dónde se han realizado, históricamente, las investigaciones sobre los medios de comunicación y para ello decide hacer un largo recorrido a través de distintos autores, corrientes de pensamiento y cánones académicos que han consagrado sus esfuerzos a estudiar y reflexionar sobre estas instituciones paradigmáticas de la modernidad.

La propuesta del autor es, sobre todo, original. Existen muchos textos que han buscado recorrer, clasificar y categorizar los trabajos que abordan el tema de los medios de comunicación; sin embargo, la ruta que sugiere Trejo tiene poca relación con otras que previamente se han planteado. Comienza por recordar las ideas que Tocqueville y Comte tuvieron sobre la prensa escrita; después vienen algunos de los apartados más interesantes de su capítulo, en los que rescata el pensamiento de Marx, Engels, Lenin y Gramsci en torno a la comunicación masiva, algo pocas veces visto en otros recuentos. El camino continúa a través de la obra de grandes autores de la sociología como Weber o de corrientes como el empirismo estadounidense o la escuela de Frankfurt. Se detiene, además, en las obras de Marshal McLuhan, Niklas Luhmann o Zygmut Bauhman. Este capítulo, pero particularmente su bibliografía, será de gran ayuda para los estudiantes de grado y posgrado que tengan en mente el amplio horizonte de los medios de comunicación, ya que es una guía básica y ecléctica sobre textos que, emplazados desde la filosofía, la sociología y los estudios políticos observan críticamente a los medios de comunicación. 
Finalmente, el tercer capítulo del libro pertenece al fundador del DECS, Enrique Sánchez Ruiz, y lleva por nombre "Recuperar la crítica. Algunas reflexiones personales en torno al estudio de las industrias culturales en Iberoamérica en los últimos decenios". El texto es amplio, diverso y bosqueja una visión crítica de los objetos de estudio del campo académico de la comunicación. Si en el primer capítulo de este libro Raúl Fuentes hace una descripción detallada del campo, Sánchez Ruiz agrega un nuevo elemento para la discusión: una suerte de historia de las ideas de este mundo académico.

En las primeras líneas del capítulo hay una precisión fundamental: "no todo lo que se considera 'comunicación' es estrictamente comunicativo. El dominio problemático que a este autor le interesa es el de los llamados 'medios de comunicación', en el contexto de las denominadas industrias culturales" (p. 123). Sánchez Ruiz, uno de los investigadores pioneros en el campo de la comunicación en México y que en su trayectoria académica destacan sus aportaciones teórico-metodológicas para estudiar a los medios de comunicación, así como sus diversas investigaciones empíricas sobre las industrias culturales, da un siguiente paso en su artículo y propone conceptos como "climas de opinión", "epistemes/paradigmas" o "espíritu del tiempo", para analizar las distintas corrientes de pensamiento que rodearon a los estudios sobre medios durante los últimos 30 años.

En la década de los años setenta, por ejemplo, el autor encuentra que "predominaron las miradas estructurales y totalizadoras, la crítica social y la utopía" y que en los años ochenta se construyó una "mirada fragmentada de la realidad histórico-social, individualismo, y de mayor conformismo" (p. 135). La contextualización que hace Sánchez Ruiz sobre los entornos políticos y económicos de estas décadas, ayuda a entender el comportamiento de estos climas de opinión académicos. En lo particular, es muy interesante la relación que establece entre el desarrollo y advenimiento de las políticas y gobiernos neoliberales y el desplazamiento, e incluso marginación, de ciertas perspectivas académicas de estudio de los medios, en especial, aquellas con una vocación crítica.

Además, Sánchez Ruiz hace una reconstrucción de la genealogía e historia de los estudios sobre medios de comunicación en América Latina y hace un llamado a realizar trabajos de investigación reflexi- 
vos, críticos y plurales en su diversidad de miradas y tradiciones; también invita a dejar de lado a los "maniqueísmos" y los "modismos" epistemológicos:

Es decir, por un lado, la tentación que tenemos de ver el mundo dividido en "blanco y negro", "buenos y malos"; y, por otro lado, el que nuestros colegas gusten de adoptar enfoque tras enfoque en un interminable desfile de modas, desechando las aportaciones previas antes de que terminen de probar su valor, que siempre será, de todos modos, relativo e incompleto (p. 142).

\section{COLOFÓN}

Aunque son tres textos distintos, los autores del libro Qué pasa con el estudio de los medios, dialogan entre sí y parten de territorios comunes. Por ejemplo, en los tres hay un cierto consenso respecto de que los medios de comunicación son un objeto de estudio que tiende a ser observado desde una diversidad de miradas disciplinarias y no desde una ciencia o disciplina en particular. Ciertamente, la postura de Trejo y de Sánchez, quienes concluyen que la base de todos estos estudios es la sociología, es distinta a la que propone Fuentes a través de la postdisciplina; sin embargo, estas diferencias no terminan por ser antagónicas. En los tres capítulos se menciona el artículo "Algunas condiciones para la investigación científica en México" (Fuentes Navarro \& Sánchez Ruiz, 1989), como un aporte fundacional para entender el campo de la comunicación, y concuerdan en que las características ahí planteadas aún subsisten dos décadas después. Finalmente coinciden en que el campo de la comunicación vive un proceso de crecimiento.

Este es un libro que, si bien tiene fallas ortotipográficas y de diseño editorial, atribuibles -supongo yo- a sus editores, vale la pena hacerse de él, como un preciado mapa que guíe a quienes buscan navegar en las aguas de los estudios de la comunicación.

\section{Bibliografía}

Fuentes Navarro, R. \& Sánchez Ruiz, E. E. (1989). Algunas condiciones para la investigación científica de la comunicación en México. Cuadernos Huella, 17. Guadalajara: ITESO. 